\title{
Maximal Oxygen Consumption in Patients with Lung Disease
}

\author{
KenNeth L. Wehr and Robert L. Johnson, JR. with the technical \\ assistance of Abraham Prengler \\ From the Adolph Weinberger Laboratory for Cardiopulmonary Research, \\ Department of Internal Medicine, The University of Texas Southwestern \\ Medical School, Dallas, Texas 75235
}

\begin{abstract}
A theoretical model for oxygen transport assuming a series linkage of ventilation, diffusion, oxygen uptake by erythrocytes, cardiac output, and oxygen release was used to calculate expected values for maximal oxygen intake $\left(\dot{V}_{O_{2 \max }}\right)$ of patients with various pulmonary disorders. 22 patients with either restrictive or obstructive ventilatory impairment were studied at rest and maximal exercise. When exercise measurements of maximal pulmonary blood flow ( $\dot{Q}_{\mathrm{Cmax}}$ ), oxygen capacity, membrane diffusing capacity for $\mathrm{CO}$, pulmonary capillary blood volume, alveolar ventilation, and mixed venous oxygen saturation were employed as input values, predictions of $\dot{V}_{O_{2 \max }}$ from the model correlated closely with measured values $(r=0.978)$. Measured $\dot{V}_{O_{2 \max }}$ was $976 \pm 389 \mathrm{ml} / \mathrm{min}$ (45.3 $\pm 13 \%$ of predicted normal), and $\dot{\mathrm{V}}_{2 \max }$ predicted from the model was $1,111 \pm 427 \mathrm{ml} / \mathrm{min}$. The discrepancy may in part reflect uneven matching of alveolar ventilation, pulmonary capillary blood flow, and membrane diffusing capacity for $\mathrm{CO}$ within the lung; uniform matching is assumed in the model so that mismatching will impair gas exchange beyond our predictions.
\end{abstract}

Although $\dot{Q}_{\mathbf{C m a x}}$ was less than predicted in most patients $(63.6 \pm 19.6 \%$ of predicted) the model suggests that raising $\dot{Q}_{\mathbf{C m a x}}$ to normal could have raised $\mathrm{Vo}_{2 \max }$ only $11.6 \pm 8.8 \%$ in the face of existent impairment of intrapulmonary gas exchange.

Since pulmonary functions measured at rest correlated well with exercise parameters needed in the model to predict $\dot{V}_{o_{2 m a x}}$ we developed a nomogram for predicting $\dot{V}_{O_{2 m a x}}$ from resting $\mathrm{CO}$ diffusing capacity, the forced one second expired volume, and the resting ratio of dead space to tidal volume. The correlation coefficient between measured and predicted $\mathrm{Vo}_{2 \mathrm{max}}$, by using this nomogram, was 0.942 .

Received for publication 16 June 1975 and in revised form 28 June 1976.

\section{INTRODUCTION}

One of the most distressing aspects of chronic lung disease for the patient is the reduced capacity for exercise. Measurements of pulmonary function are used widely to detect lung disease, to estimate the pattern and severity of functional involvement, and to follow the course of disease and response to treatment; but in spite of sophisticated measurements we still cannot objectively judge whether a given pattern and severity of functional abnormalities can account for a patient's reduction in exercise capacity.

Our purpose has been to examine the utility of the simple hypothesis that impaired lung function limits exercise by imposing a bottleneck in the chain of oxygen transport, thereby restricting the maximal rate of oxygen delivery to exercising muscle. We (1) constructed a mathematical model of oxygen transport as a simple series linkage of ventilation, diffusion, blood flow, and tissue oxygen release, (2) employed this model in patients with a variety of lung disorders to predict a theoretical maximal oxygen intake $\left(\mathrm{Vo}_{2 \max }\right)^{1}$ based on measurements of ventilatory capacity, and the ratio of dead space to tidal volume $\left(V_{D} / V_{T}\right)$ assuming normal maximal cardiac output and tissue oxygen release, and (3) compared the predictions with experimental measurements. Except for the inhomogeneity implied by an increased ratio of $V_{D} / V_{T}$ we have assumed homogeneous matching of blood flow, ventilation, and diffusing capacity throughout the lungs. By measuring blood gases and cardiac output at peak exercise in the same patients, it has been possible to

\footnotetext{
${ }_{1}$ Abbreviations used in this paper: $\mathrm{FEV}_{1}$, forced $1 \mathrm{~s}$ expiratory volume; $M$, membrane; $M V C$, maximal ventilatory capacity; $\mathrm{P}$, tension; $\mathrm{PCO}_{2}$, intracorpuscular $\mathrm{O}_{2}$ tension; $\mathrm{Qc}$, pulmonary capillary blood flow; $Q_{\text {cmax }}$, maximal pulmonary blood flow; $\mathrm{Sc}^{\prime} \mathrm{O}_{2}$, end-capillary oxygen saturation; TLC, total lung capacity; $\dot{V}_{\mathbf{A}}$, alveolar ventilation; $\mathrm{V}_{\mathbf{C}}$, pulmonary capillary blood volume; $\dot{\mathrm{V}}_{\mathrm{Emax}}$, maximal ventilation; $\mathrm{VO}_{2 \max }$, maximal oxygen intake.
} 
examine some sources of discrepancy between prediction and measurement. Finally, we have examined the reliability of using resting measurements of lung function in this model as a means of estimating exercise impairement attributable to the lung.

\section{METHODS}

Theory. This is an extension of previous theoretical considerations of oxygen transport in normal persons at high altitude (1) and is similar to the approach proposed by Shephard (2). The major links in the chain of oxygen transport from the lungs to the cells are (1) ventilation, (2) diffusion, (3) oxygen uptake by erythrocytes, (4) distribution by the cardiac output, and (5) extraction by the tissues. The mathematical interrelationships that govern the linkage of these steps are summarized as follows: the relationship among alveolar oxygen tension $\left(\mathrm{PAO}_{2}\right)$, alveolar ventilation $\left(\mathrm{V}_{\mathbf{A}}\right)$, and oxygen consumption $\left(\mathrm{Vo}_{2}\right)$ may be expressed by the following modification of the alveolar air equation:

$$
\mathrm{PAO}_{2}=\mathrm{PIO}_{2}-\left(863 / \dot{\mathrm{V}}_{\mathrm{A}}\right)\left[1-\mathrm{FIO}_{2}(1-\mathrm{R})\right] \dot{\mathrm{V} \mathrm{O}_{2}}
$$

Equation 1 defines a linear relationship between $\mathrm{PAO}_{2}$ and $\dot{\mathrm{V}}_{2}$ for any given level of $\dot{\mathrm{V}}_{\mathrm{A}}$ and respiratory quotient (R) under steady state conditions and simply states that for fixed levels of $\dot{V}_{A}$ and $R$ the oxygen consumption can be increased only at the expense of a falling alveolar oxygen tension.

The time interval $(t)$ required for the oxygen saturation $\left(\mathrm{SO}_{2}\right)$ of blood passing through the lung capillaries to rise between that in mixed venous and end-capillary blood can be estimated as follows $(3,4)$ :

$$
\begin{aligned}
t=(\operatorname{cap}) \int_{\mathrm{S}_{\overline{\mathrm{VO}} 2}}^{\mathrm{Sc}^{\prime} \mathrm{O}_{2}}\left\{\left[\left(\mathrm{~V}_{\mathrm{c}} / \mathrm{DM}_{\mathrm{O}_{2}}\right)\right.\right. & \left.+\left(1 / \theta \mathrm{O}_{2}\right)\right] \\
& \left.\times\left[\mathrm{dScO}_{2} /\left(\mathrm{PAO}_{2}-\mathrm{PCO}_{2}\right)\right]\right\}
\end{aligned}
$$

where $t=$ time interval in minutes; cap $=$ oxygen capacity of blood in $\mathrm{ml} \mathrm{O}_{2}$ per $100 \mathrm{ml}$ of blood; $\mathrm{ScO}_{2}=$ fractional oxygen saturation of capillary blood in the lung; $\mathrm{S}_{\bar{v}} \mathrm{O}_{2}=$ fractional mixed venous blood oxygen saturation; $\mathrm{Sc}^{\prime} \mathrm{O}_{2}=$ fractional end-capillary blood oxygen saturation in the lung; $\mathrm{V}_{\mathrm{C}}$ = pulmonary capillary blood volume in milliliters; $\mathrm{DM}_{\mathrm{O}_{2}}$ = membrane diffusing capacity for oxygen in milliliters/ minute per $\mathrm{mm} \mathrm{Hg} \mathrm{O}_{2}$ tension difference across the alveolar capillary membrane; $\theta \mathrm{O}_{2}=$ specific rate of $\mathrm{O}_{2}$ uptake by erythrocytes in capillary blood in $\mathrm{ml} \mathrm{O}_{2}$ uptake per minute per milliliter of blood per $\mathrm{mm} \mathrm{Hg} \mathrm{O} \mathrm{O}_{2}$ tension difference between plasma and the intracorpuscular hemoglobin; $\mathrm{PAO}_{2}-\mathrm{PCO}_{2}=$ difference between alveolar and intra-corpuscular $\mathrm{O}_{2}$ tension in $\mathrm{mm} \mathrm{Hg}$.

$\mathrm{V}_{\mathrm{C}}$, pulmonary capillary blood flow $\left(\dot{Q}_{\mathrm{c}}\right)$, and transit time $(t)$ are related as follows:

$$
\dot{\mathrm{Q}}_{\mathrm{c}}=\left(\mathrm{V}_{\mathrm{c}}\right) / t
$$

The Fick equation states that

$$
\dot{\mathrm{V}}_{2}=\dot{\mathrm{Q}}_{\mathrm{c}}\left(\mathrm{Sc}^{\prime} \mathrm{O}_{2}-\mathrm{S}_{\overline{\mathrm{V}}} \mathrm{O}_{2}\right)(\mathrm{cap}) / 100
$$

Combining equations 3 and 4

$$
\dot{\mathrm{Vo}}_{2}=\mathrm{V}_{\mathrm{C}}\left(\mathrm{Sc}^{\prime} \mathrm{O}_{2}-\mathrm{S}_{\overline{\mathrm{V}}} \mathrm{O}_{2}\right)(\mathrm{cap}) / 100 t
$$

The mixed venous oxygen saturation in equation 5 is determined in part by how efficiently the cardiac output is distributed with respect to regional oxygen consumption and in part by regional capillary densities which regulate the endcapillary oxygen tension that can be sustained at a given oxygen consumption. At peak exercise normal persons can release to the tissues $70-80 \%$ of the oxygen that is delivered
TABLE I

Parameters Employed in the Model to Predict $\dot{\mathrm{V}}_{2 \max }$

Approximations employed in the nomogram

(1) $\dot{Q}_{\mathrm{Cmax}}$

Normal predicted

$\dot{\mathrm{V}}_{2 \max } / 0.15$

(2) $\dot{V}_{E \max }$

$\mathrm{FEV}_{1} \times 35$

(3) $\mathrm{V}_{\mathrm{D}} / \mathrm{V}_{\mathrm{T}}$

Resting $\mathrm{V}_{\mathbf{D}} / \mathrm{V}_{\mathbf{T}}$

(4) Membrane diffusing capacity for $\mathrm{O}_{2}\left(1.2 \times \mathrm{DM}_{\mathrm{CO}}\right)$

Resting diffusing capacity for $\mathrm{CO}\left(\mathrm{DL}_{\text {co }} \times 2.16\right)$

(5) $\mathrm{V}_{\mathrm{c}}$

Resting $\mathrm{DL}_{\text {co }} \times 4.95$

(6) $\mathrm{SV}_{\mathrm{V}} \mathrm{O}_{2}$

Pulmonary end capillary $\mathrm{O}_{2}$ saturation $\left(\mathrm{Sc}^{\prime} \mathrm{O}_{2}\right)$ $\times 0.25$

(7) $\mathrm{O}_{2}$ cap

Resting $\mathrm{O}_{2}$ capacity

(8) $\mathrm{R}$

(9) $\mathrm{pHa}$

and mixed venous oxygen tension falls to between 10 and 20 $\mathrm{mm} \mathrm{Hg}$. Combining equations 2 and 5 and assuming that $\mathrm{DM}_{2}=1.2 \mathrm{DMco}$, we obtain:

$$
\dot{V_{0}}=\frac{\mathrm{V}_{\mathrm{C}}\left(\mathrm{Sc}^{\prime} \mathrm{O}_{2}-\mathrm{S}_{\bar{v} O_{2}}\right)}{\int_{\mathrm{S}_{\overline{\mathrm{VO}} 2}}^{\mathrm{Sc}^{\prime} \mathrm{O}_{2}}\left(\frac{\mathrm{V}_{\mathrm{C}}}{1.2 \mathrm{DMMO}_{\mathrm{CO}}}+\frac{1}{\theta \mathrm{O}_{2}}\right) \frac{\mathrm{dSO}_{2}}{\left(\mathrm{PAO}_{2}-\mathrm{PcO}_{2}\right.}}
$$

A digital computer was employed to solve equations 1,4 , and 6 simultaneously for the matrix of input values given in Table I.

Initially the measured exercise values of each input parameter listed in the left hand column of Table I were employed in the model. Later approximations to these input parameters (right hand column of Table I) were employed to derive a nomogram for predicting $\dot{\mathrm{V}}_{2 \max }$ from resting lung function.

Experiments. Table II lists the physical characteristics and diagnoses of the study patients. The 22 patients included 9 women and 13 men. One (J. J.) was studied twice over $9 \mathrm{yr}$, making a total of 23 studies. Six of the patients had chronic obstructive pulmonary diseases, eight had sarcoidosis of varying severity, three had interstitial fibrosis of unknown etiology, three had extensive pulmonary resections for tuberculosis, one had advanced inactive tuberculosis with diffuse interstitial fibrosis, and one had a unilateral hyperlucent lung. The average was $39.3 \mathrm{yr}$ with a range of $18-69 \mathrm{yr}$. Only one patient (E. T.) had evidence of primary heart disease (severe coronary artery atherosclerosis without occlusion or infarction) proven later at postmortem (5).

Each patient underwent an exercise training program of at least 3 wk duration or until a reproducible maximal work load was achieved. Some results in eight of these patients (footnoted in Table II) have been reported in earlier studies from this laboratory $(4,6)$. Training and exercise during the studies were performed either on a motor-driven treadmill or on a Monark bicycle ergometer (Monark-Crescent AB, Varberg, Sweden) with patients breathing room air $\left(\mathrm{P}_{\mathrm{I}_{2}}\right.$ $\cong 150 \mathrm{~mm} \mathrm{Hg}$ ) or $100 \%$ oxygen from a reservoir bag. The maximal oxygen consumption was defined as the oxygen uptake during the last minute of the heaviest work load that could be sustained for $3.5 \mathrm{~min}$ on the treadmill or for $5 \mathrm{~min}$ on the bicycle ergometer (7). Expired gas was collected in a 
TABLE II

Physical Characteristics and Diagnoses of Study Patients

\begin{tabular}{|c|c|c|c|c|c|c|c|c|c|c|}
\hline Patient & Race & Sex & Age & Height & Weight & TLC & FVC & FEV $_{1}$ & $\mathbf{P}_{\max }$ & Diagnosis \\
\hline & & & yr & $\mathrm{cm}$ & kg & liter & liter & liter & $\mathrm{Cm} \mathrm{H}_{2} \mathrm{O}$ & \\
\hline \multicolumn{11}{|c|}{ Obstructive disease } \\
\hline I. M. & C & $\mathbf{M}$ & 51 & 173 & 47.2 & 6.60 & 2.15 & 0.65 & 18 & COPD \\
\hline W. B. & C & M & 60 & 182 & 69.0 & 6.52 & 1.49 & 0.63 & 4 & COPD \\
\hline R. E. & $\mathrm{C}$ & $\mathbf{M}$ & 46 & 169 & 61.0 & 9.53 & 2.96 & 0.94 & 6 & COPD \\
\hline W. T. & C & $\mathbf{M}$ & 50 & 183 & 92.1 & 8.04 & 4.72 & 1.13 & 14 & COPD \\
\hline J. N. & C & $\mathbf{M}$ & 58 & 178 & 72.3 & 6.70 & 3.47 & 1.14 & & COPD \\
\hline J. S. & C & $\mathbf{M}$ & 42 & 173 & 63.7 & 6.22 & 2.55 & 0.92 & 18 & COPD \\
\hline Mean & & & 51 & 176 & 76.6 & 7.27 & 2.89 & 0.90 & & \\
\hline SE & & & 7 & 6 & 14.8 & 1.28 & 1.12 & 0.22 & & \\
\hline \multicolumn{11}{|c|}{ Restrictive disease } \\
\hline J. J. $-1960^{*}$ & $\mathbf{N}$ & F & 32 & 150 & 41.0 & 3.62 & 2.02 & 1.52 & & Sarcoidosis \\
\hline J. J. -1969 & & & 41 & 150 & 37.2 & 4.50 & 2.23 & 1.28 & & Sarcoidosis \\
\hline $\mathrm{CMcD}^{*}$ & $\mathbf{N}$ & $\mathbf{M}$ & 18 & 175 & 59.1 & 4.41 & 3.22 & 2.90 & & Sarcoidosis \\
\hline J. A.* & $\mathbf{N}$ & $\mathbf{M}$ & 18 & 180 & 61.0 & 3.55 & 2.65 & 2.20 & & Sarcoidosis \\
\hline R. J. & $\mathrm{N}$ & $F$ & 35 & 173 & 63.7 & 3.92 & 2.30 & 1.09 & & Sarcoidosis \\
\hline W. J. & $\mathrm{N}$ & $\mathrm{F}$ & 32 & 183 & 86.4 & 3.36 & 2.10 & 1.72 & & Sarcoidosis \\
\hline H. C. & $\mathrm{N}$ & $\mathbf{M}$ & 24 & 182 & 57.8 & 3.25 & 1.99 & 1.49 & & Sarcoidosis \\
\hline R. P. & $\mathrm{N}$ & $\mathbf{F}$ & 24 & 164 & 50.1 & 2.24 & 1.50 & 1.02 & & Sarcoidosis \\
\hline G. J. & $\mathbf{N}$ & $\mathrm{F}$ & 23 & 164 & 65.8 & 3.84 & 2.89 & 2.03 & & Sarcoidosis \\
\hline A. D. & $\mathrm{N}$ & $F$ & 32 & 165 & 61.4 & 2.77 & 2.21 & 1.47 & & Tuberculosis \\
\hline E. T.* & C & $\mathbf{M}$ & 69 & 173 & 84.0 & 3.79 & 2.62 & 1.88 & & Int fibrosis \\
\hline W. E. & C & $\mathbf{M}$ & 54 & 163 & 80.0 & 3.94 & 2.61 & 1.99 & & Int fibrosis \\
\hline P. B.* & $\mathrm{C}$ & M & 44 & 170 & 59.1 & & 2.95 & 2.21 & & Int fibrosis \\
\hline R. H.f & C & F & 47 & 153 & 59.5 & 1.94 & 1.31 & 0.93 & & Lung resection \\
\hline M. G.t & LA & $F$ & 41 & 150 & 43.2 & 2.76 & 1.92 & 0.97 & & Lung resection \\
\hline R. W. & $\mathrm{N}$ & $F$ & 29 & 163 & 54.5 & 2.77 & 1.90 & 1.53 & & Lung resection \\
\hline J. W. & C & $\mathbf{M}$ & 18 & 168 & 59.4 & 3.97 & 2.68 & 1.83 & & Unil hyp lung \\
\hline Mean & & & 34 & 166 & 60.2 & 3.51 & 2.30 & 1.65 & & \\
\hline SE & & & 14 & 11 & 13.7 & 0.70 & 0.51 & 0.53 & & \\
\hline
\end{tabular}

Abbreviations: TLC, total lung capacity ; FVC, forced vital capacity, $F_{E V}$, forced 1 s expired volume ; $P_{\max }$, recoil pressure of the lungs at full inspiration; COPD, chronic obstructive lung disease; Unil hyp lung, unilateral hyperlucent lung.

* From reference 4.

$\ddagger$ From reference 6 .

150-liter Douglas bag utilizing a low-resistance modified Otis-McKerrow valve (no. P-339). The gases were analyzed with a Beckman model E-2 oxygen analyzer and a Beckman model LB-1 medical carbon dioxide gas analyzer. (Beckman Instruments Inc., Fullerton, Calif.) Both analyzers were calibrated with gas standards analyzed by the Scholander technique (8). Gas volumes were measured with a Tissot gasometer. An arterial sample was obtained near the midpoint of the last minute of exercise. A calibrated Beckman model 160 blood gas analyzer was utilized to determine arterial blood $\mathrm{pH}, \mathrm{Po}_{2}$, and $\mathrm{PCO}_{2}$. Oxygen saturations were determined with an American Optical reflection oximeter in some patients; in others oxygen saturations were calculated from oxygen capacities and contents measured by Van Slyke analysis. Cardiac outputs were performed in some patients at rest and exercise with indocyanine green dye by the dyedilution technique during the last $\frac{1}{2} \mathrm{~min}$ of the expired gas collection. Spirometry was performed with a Stead-Wells spirometer. The total lung capacity and subdivisions of the lung volume were determined from the spirometry and the functional residual capacity determined by the volume plethysmograph method of DuBois et al. (9). The diffusing capacity of the lung and pulmonary capillary blood flow were determined at rest by a single-breath method described in detail elsewhere $(4,10)$. At peak exercise $D_{L_{c o}}$ and $Q_{c}$ were measured either by the breath-holding method or by a modification of the rebreathing method described by Lawson (11). Alveolar volume during breath-holding was estimated by single breath neon dilution. Measurements of DLco were repeated at low and high oxygen tensions so that membrane diffusing capacity (DMco) and $\mathrm{V}_{\mathrm{C}}$ could be estimated (12).

\section{RESULTS}

Lung volumes at rest and measurements of diffusing capacity, pulmonary capillary blood volume, flow, and heart rate at rest and peak exercise are listed for each patient in Table III. Ventilation, blood gases, $\mathrm{pH}$, and gas exchange measurements at rest and exercise are given in Table IV.

The patients have been separated into two groups, one including those having lung disorders associated with predominantly obstructive ventilatory defects, and the other those having disorders associated with predominantly restrictive defects and loss of diffusing capacity. Both groups showed similar reductions in 


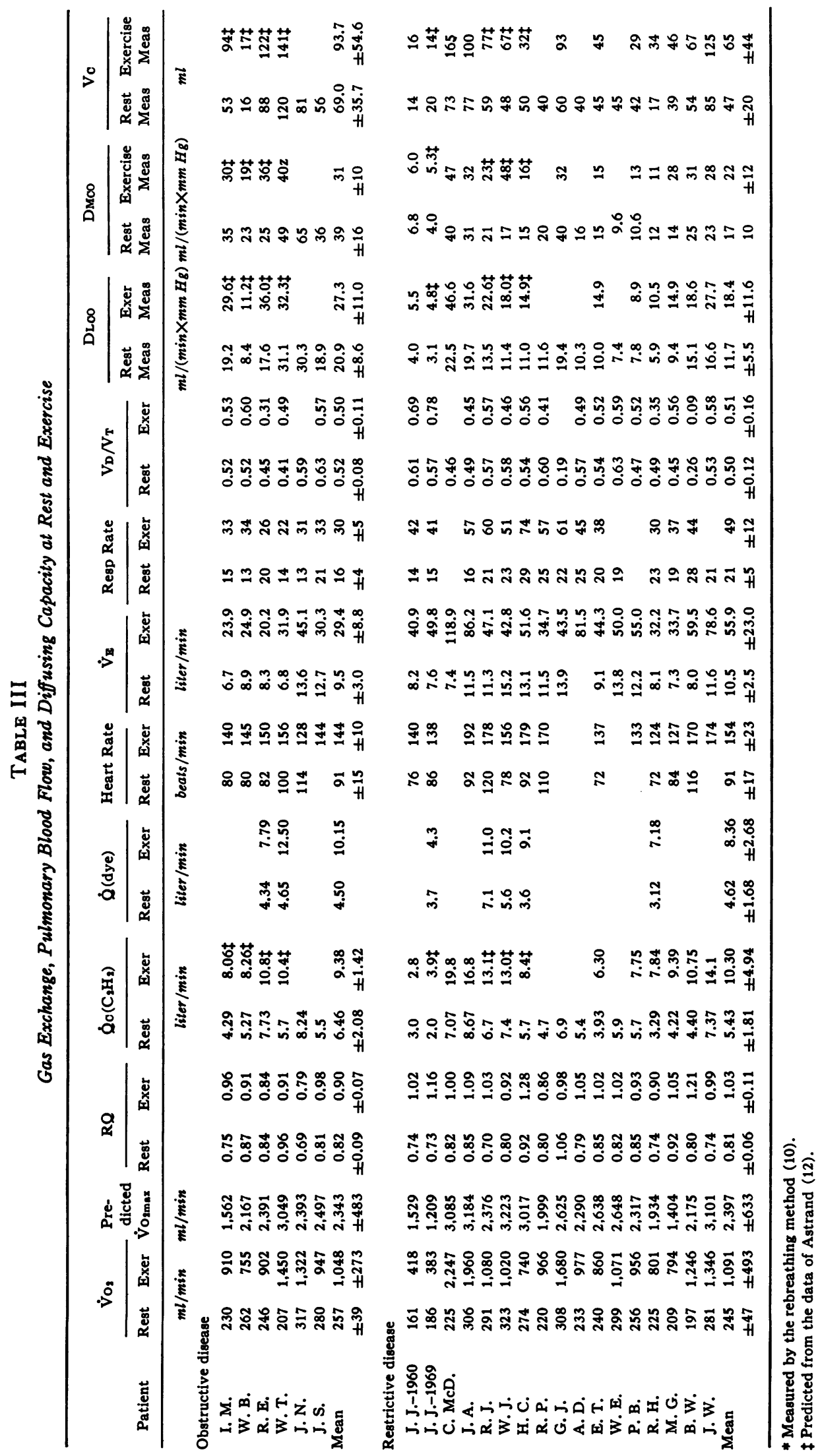


TABLE IV

Blood Gases at Rest and Exercise

\begin{tabular}{|c|c|c|c|c|c|c|c|c|c|c|c|c|c|c|c|c|c|c|c|c|c|c|}
\hline \multirow[b]{2}{*}{ Patient } & \multicolumn{2}{|c|}{$\mathrm{O}_{2} \mathrm{Cap}$} & \multicolumn{2}{|c|}{$\mathrm{pHa}$} & \multicolumn{2}{|c|}{$\mathrm{PaCO}_{2}$} & \multicolumn{2}{|c|}{$\mathrm{PAO}_{2}$} & \multicolumn{2}{|c|}{$\begin{array}{l}\text { Breathing air } \\
\qquad \mathrm{PaO}_{2}\end{array}$} & \multicolumn{2}{|c|}{$\mathrm{SaO}_{2}$} & \multicolumn{2}{|c|}{$\mathrm{Sc}^{\prime} \mathrm{O}_{2} *$} & \multicolumn{2}{|c|}{$\mathrm{S}_{\overline{\mathrm{V}} \mathrm{O}_{2}} \ddagger$} & \multicolumn{2}{|c|}{$\mathrm{P}_{\overline{\mathrm{v}} \mathrm{O}_{2}}$} & \multicolumn{4}{|c|}{$\begin{array}{l}\text { Breathing } 100 \% \mathrm{O}_{2} \\
\mathrm{PaCO}_{2} \quad \mathrm{PAO}_{2}-\mathrm{PaO}\end{array}$} \\
\hline & Rest & Exer & Rest & Exer & Rest & Exer & Rest & Exer & Rest & Exer & Rest & Exer & Rest & Exer & Rest & Exer & Rest & Exer & Rest & Exer & Rest & Exer \\
\hline & \multicolumn{2}{|c|}{$\mathrm{ml} / 100 \mathrm{ml}$} & & & \multicolumn{2}{|c|}{$m m H g$} & \multicolumn{2}{|c|}{$m m H g$} & $m m$ & $\mathrm{Hg}$ & \multicolumn{2}{|c|}{$\%$} & \multicolumn{2}{|c|}{$\%$} & \multicolumn{2}{|c|}{$\%$} & \multicolumn{2}{|c|}{$m m H_{g}$} & \multicolumn{2}{|c|}{$m m H g$} & \multicolumn{2}{|c|}{$m m \mathrm{Hg}$} \\
\hline \multicolumn{23}{|c|}{ Obstructive disease } \\
\hline I. M. & 19.9 & & 7.45 & 7.21 & 46 & 67 & 99 & 78 & 49 & 52 & 87.0 & 77.0 & 89.2 & $77.7 \|$ & 57.3 & 19.3 & 29 & 16 & 53 & 78 & 147 & 46 \\
\hline W. B. & 21.6 & & 7.41 & 7.31 & 46 & 60 & 96 & 82 & 58 & 50 & 90.0 & 81.0 & 91.2 & $83.3 \|$ & 65.1 & 36.0 & 35 & 23 & 56 & 81 & 93 & 163 \\
\hline R. E. & 17.8 & & 7.43 & 7.31 & 39 & 47 & 102 & 93 & 76 & 64 & 94.7 & 89.3 & 94.7 & $89.5 \|$ & 72.0 & 41.7 & 39 & 26 & 47 & 66 & 0 & 14 \\
\hline W. T. & 23.2 & & 7.44 & 7.20 & 43 & 70 & 102 & 70 & 48 & 57 & 85.0 & 81.0 & 85.7 & $82.2 \|$ & 60.7 & 19.5 & 31 & 16 & 54 & 76 & 59 & 89 \\
\hline J. N. & 17.0 & & 7.43 & & 37 & & 108 & & 73 & & 95.0 & & 95.9 & & & & & & 42 & & 63 & \\
\hline J. S. & 18.0 & & 7.38 & 7.23 & 42 & 62 & 97 & 84 & 60 & 58 & 87.0 & 77.0 & 91.6 & $79.8 \|$ & & & & & 46 & 67 & 276 & 157 \\
\hline Mean & 19.6 & & 7.42 & 7.25 & 42 & 61 & 101 & 81 & 61 & 56 & 89.8 & 81.1 & 91.4 & 82.5 & 63.8 & 29.1 & 34 & 20 & 50 & 74 & 107 & 94 \\
\hline SD & 2.4 & & 0.03 & 0.05 & 4 & 9 & 4 & 8 & 12 & 6 & 4.2 & 5.0 & 3.7 & 4.5 & 6.4 & 11.5 & 4 & 5 & 5 & 7 & 81 & 66 \\
\hline Restrictive & sease & & & & & & & & & & & & & & & & & & & & & \\
\hline J. J. -1960 & 20.0 & 20.8 & 7.45 & 7.48 & 32 & 29 & 108 & 118 & 74 & 47 & 88.7 & 74.7 & 91.0 & 77.1 & 59.6 & 0.8 & 30.6 & 1 & 32 & 33 & 139 & 157 \\
\hline J. J. -1969 & 17.0 & 17.4 & 7.47 & 7.43 & 36 & 35 & 104 & 116 & 46 & 34 & 81.4 & 63.6 & 83.1 & 71.9 & 50.7 & 1.5 & 25.8 & 2 & 34 & 42 & 97 & $441 *$ \\
\hline C. M. $\mathrm{cD}$ & 18.3 & & 7.46 & & 40 & & 102 & & 75 & & 97.3 & & 97.4 & & & & & & 41 & & 30 & \\
\hline J. A. & 20.0 & 20.7 & 7.52 & 7.49 & 38 & 39 & 105 & 112 & 61 & 65 & 94.0 & 91.5 & 94.7 & 92.6 & 74.9 & 33.9 & 37.7 & 18 & 37 & 44 & 54 & 73 \\
\hline R. J. & 17.1 & 17.8 & 7.44 & 7.32 & 36 & 47 & 100 & 102 & 65 & 51 & 90.8 & 81.3 & 92.0 & 82.8 & 67.2 & 37.7 & 35.3 & 24 & 39 & 48 & 64 & 88 \\
\hline W. J. & 16.5 & 17.2 & 7.42 & 7.37 & 35 & 35 & 95 & 110 & 75 & 45 & 93.7 & 80.4 & 95.3 & 82.6 & 63.1 & 29.7 & 33.5 & 19 & 31 & 39 & 90 & 130 \\
\hline H. C. & 18.9 & 19.0 & 7.40 & 7.38 & 36 & 36 & 110 & 115 & 73 & 61 & 91.8 & 89.2 & 93.3 & 90.3 & 62.3 & 40.8 & 33.8 & 24 & 34 & 40 & 93 & 71 \\
\hline R. P. & 17.9 & & 7.36 & 7.38 & 33 & 35 & 99 & 105 & 83 & 68 & 97.5 & 92.1 & 98.4 & 93.7॥ & & & & & 35 & 43 & 97 & 104 \\
\hline G. J. & 18.9 & & 7.57 & & 25 & & 123 & & 94 & & 93.2 & & 95.0 & & & & & & 23 & & 84 & \\
\hline A. D. & 14.8 & 16.0 & 7.40 & 7.27 & 32 & 38 & 108 & 111 & 77 & 49 & 91.6 & 68.0 & 93.6 & 69.9 ป & & & & & 30 & & 93 & \\
\hline E. T. & 20.0 & 21.2 & 7.44 & 7.47 & 39 & 37 & 101 & 111 & 69 & 49 & 88.3 & 73.8 & 89.3 & 74.9 & 56.6 & 2.6 & 29.4 & 2 & 43 & 49 & 58 & 65 \\
\hline W. E. & 20.6 & 20.3 & 7.39 & 7.36 & 43 & 46 & 100 & 104 & 72 & 45 & 93.8 & 73.3 & 95.5 & $75.3 \pi$ & & & & & 53 & & 128 & \\
\hline P. B. & 19.3 & 19.8 & 7.52 & 7.48 & 29 & 28 & 114 & 117 & 66 & 48 & 95.0 & 88.0 & 95.0 & 88.6 & 71.4 & 24.6 & 35.2 & 15 & 31 & 32 & 1 & 45 \\
\hline R. H. & 20.3 & 21.3 & 7.49 & 7.48 & 35 & 37 & 97 & 103 & 80 & 55 & 95.8 & 84.0 & 96.0 & 85.9 & 61.4 & 34.0 & 30.3 & 19 & 38 & 42 & 14 & 125 \\
\hline M. G. & 17.5 & 17.5 & 7.42 & 7.29 & 42 & 48 & 96 & 102 & 90 & 75 & 95.8 & 91.2 & 96.5 & 92.7 & 66.4 & 41.1 & 35.5 & 26 & 43 & 58 & 27 & 77 \\
\hline B. W. & 17.3 & 17.6 & 7.50 & 7.41 & 23 & 24 & 117 & 124 & 89 & 72 & 94.5 & 94.4 & 96.4 & 95.5 & 66.2 & 26.9 & 32.6 & 17 & 24 & 26 & 101 & 74 \\
\hline J. W. & 16.8 & 16.8 & 7.42 & 7.36 & 33 & 35 & 108 & 110 & 100 & 69 & 96.8 & 92.2 & 98.2 & 93.9 & 71.7 & 33.0 & 39.2 & 21 & 36 & 38 & 90 & 102 \\
\hline Mean & 18.4 & 19.0 & 7.45 & 7.40 & 35 & 37 & 105 & 111 & 76 & 56 & 92.9 & 82.5 & 94.2 & 84.5 & & & 33 & 16 & 36 & 41 & 74 & 119 \\
\hline SD & 1.4 & 1.7 & 0.05 & 0.07 & 5 & 7 & 8 & 7 & 13 & 12 & 4.0 & 9.8 & 3.8 & 8.8 & & & 4 & 9 & 7 & 8 & 39 & 101 \\
\hline
\end{tabular}

* Calculated from the measured Saol on air and the $\left(\mathrm{PAO}_{2}-\mathrm{PaO}_{2}\right)$ measured breathing $100 \%$ oxygen by

$$
\mathrm{Sc}^{\prime} \mathrm{O}_{2}=\mathrm{SaO}_{2}+\left[\frac{0.0031\left(\left(\mathrm{PAO}_{2}-\mathrm{PaO}_{2}\right)_{\mathrm{On} 100 \% \mathrm{O}_{2}}-\mathrm{Pc}^{\prime} \mathrm{O}_{2}\right)}{\mathrm{O}_{2} \mathrm{cap}}\right] 1
$$

‡ Calculated from the $\mathrm{Sc}^{\prime} \mathrm{O}_{2}, \dot{\mathrm{V}} \mathrm{o}_{2}$, and $\dot{\mathrm{Q}}$. by $\mathrm{Svo}_{2}=\mathrm{Sc}^{\prime} \mathrm{o}_{2}-\left(100 / \mathrm{O}_{2} \mathrm{cap}\right) \times\left(\dot{\mathrm{V}}_{2} / \dot{\mathrm{Q}}_{\mathrm{c}}\right)+0.0031\left(\mathrm{Pc}^{\prime} \mathrm{O}_{2}-\mathrm{Pvo}_{2}\right)$.

$\$$ Calculated from $\mathrm{S}_{\overline{\mathrm{V}}}$ and $\mathrm{pH}_{\overline{\mathrm{v}}} \cdot \mathrm{pH} \overline{\mathrm{v}}$ is calculated from the mixed venous $\mathrm{CO}_{2}$ content (estimated from the Fick equation) and the whole blood buffer base.

$\|$ Calculated assuming that the exercise $\mathrm{O}_{2}$ is cap the same as that at rest.

I Calculated assuming that the measured $\left(\mathrm{PAO}_{2}-\mathrm{PaO}_{2}\right)$ breathing oxygen at rest applies to exercise also.

** This large gradient was due predominantly to an intracardiac shunt caused by opening of a patent foramen ovale.

$\dot{V}_{o_{m a x}}$, the average being $44.3 \%$ of that predicted for normal subjects of similar sex, age, and weight (13). Both groups showed similar drops in arterial oxygen saturation from rest to exercise. However, those with obstructive defects developed $\mathrm{CO}_{2}$ retention at peak exercise associated with a fall in alveolar oxygen tension and those with predominantly restrictive disease generally had normal or low arterial $\mathrm{CO}_{2}$ tensions during exercise with a normal or high alveolar oxygen tension.

The average 1-s forced expiratory volume $\left(\mathrm{FEV}_{1.0}\right)$ was reduced to $24 \%$ of normal in patients with obstructive disease and to $50 \%$ of normal in patients with predominantly restrictive disease; the $\mathrm{FEV}_{1.0}$ was closely related to the maximal ventilation achieved at peak exercise in both groups of patients $\left[\mathrm{V}_{\mathbf{E}}\right.$ (liter/minute) $=35.5 \mathrm{FEV}_{1.0}$ (liters) $\left.\left.-2.7, r=0.871\right)\right]$. Burrows et al. found the maximal ventilatory capacity (MVC) approximated by $38 \times \mathrm{FEV}_{1.0}$ in patients with chronic obstructive lung disease (14). Miller et al. (15) found $41 \times \mathrm{FEV}_{1.0}$ to give a good approximation of the MVC in normal subjects and patients. Both of the latter methods for estimating MVC from the $\mathrm{FEV}_{1}$ yield values that on average are larger than the maximal ventilations we observed at peak exercise; however, other investigators indicate that the maximal ventilation that can be sustained for $\mathbf{4 - 5} \mathrm{min}$ is only $80-85 \%$ of that which can be sustained for a 15-s MVC (16). Hence, patients were probably functioning at or near their maximal capacity for sustained ventilation. The fraction of ventilation effectively participating in gas exchange (i.e., $1-V_{D} / V_{T}$ ) was abnormally low at rest and was not significantly changed by exercise. Membrane diffusing capacity at rest was on average $49 \%$ of normal in the patients with predominantly obstructive disease and $30 \%$ of normal in those with 
predominantly restrictive disease. Membrane diffusing capacity changed little from rest to peak exercise.

The relationship of pulmonary blood flow to oxygen consumption was normal or slightly high in most patients (Fig. 1) but the maximal blood flow achieved was significantly reduced to an average of $57.9 \%$ of that predicted. Average mixed venous oxygen tension and mixed venous oxygen saturation at peak exercise were $16.8 \mathrm{~mm} \mathrm{Hg}$ and $26.4 \%$, respectively; an average of $69.4 \%$ of the delivered oxygen was extracted in tissues. These values are not significantly different from those previously observed in our laboratory in normal untrained subjects at peak exercise $(18,19)$.

15 of the patients had complete studies at rest and exercise allowing application of the mathematical model to the prediction of $\dot{\mathrm{V}}_{2 \max }, \mathrm{PaCO}_{2}, \mathrm{PAO}_{2}$, and $\mathrm{Sc}^{\prime} \mathrm{O}_{2}$ based entirely on exercise measurements; there were a total of 16 studies on these patients. In the remaining seven patients measurements during maximal exercise were incomplete.

Figs. 2 and 3 summarize the results obtained in the 16 complete studies comparing predictions from the mathematical model for $\mathrm{VO}_{2 \mathrm{max}}, \mathrm{PaCO}_{2}, \mathrm{PAO}_{2}$ and $\mathrm{Sc}^{\prime} \mathrm{O}_{2}$ at peak exercise with the measured values. Employing the input parameters (Table I) measured at peak exercise for making our predictions (prediction no. 1 in Fig. 2), highly significant correlations were obtained between measurements and predictions of $\dot{\mathrm{V}}_{2 \max }, \mathrm{PaCO}_{2}, \mathrm{PAO}_{2}$ and $\mathrm{Sc}^{\prime} \mathrm{O}_{2}$. The model could account for most of the observed reduction in $\dot{V}_{2 \max }$ as well as for most of the variance among subjects $(r=0.978)$. To examine how critical each step in the oxygen transport chain was in reducing $\dot{V}_{O_{2 m a x}}$ and in explaining the variances in $\mathrm{PAO}_{2}, \mathrm{PaCO}_{2}$, and $\mathrm{Sc}^{\prime} \mathrm{O}_{2}$ at peak exercise, we repeated the predictions in each patient by successively employing normal input parameters in the model for maximal pulmonary blood flow ( $\left.\dot{Q}_{\mathrm{Cmax}}\right)$,

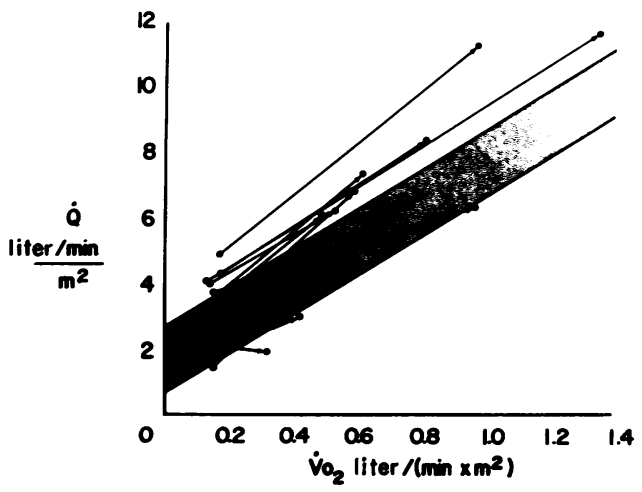

Figure 1 Relationship between cardiac output ( $\dot{Q})$ and oxygen consumption at rest and exercise in the patients compared with the normal range $( \pm 2 S D)$ for upright subjects (17).
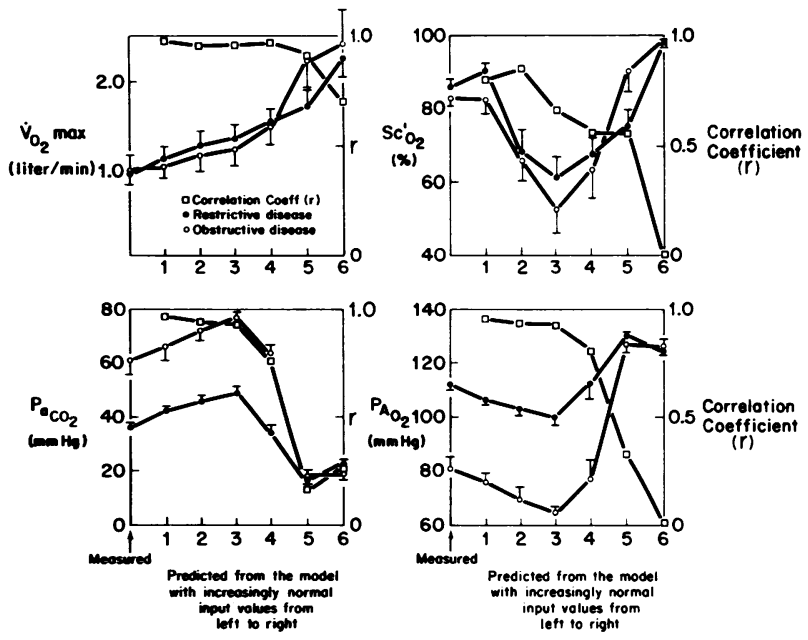

Figure 2 Average measurements at peak exercise for $\mathrm{Vo}_{2 \max }, \mathrm{Sc}^{\prime} \mathrm{O}_{2}, \mathrm{PaCO}_{2}$, and $\mathrm{PAO}_{2}$ compared with corresponding averages predicted from the model by using different input data as defined below. Average measured values are indicated on the vertical axis to the left in each graph. Vertical bars through each mean reflect $\pm 1 \mathrm{sD}$. Input data for prediction 1 from the model were measured values at peak exercise of the input parameters listed in the first column of Table I. Normal predicted values for these input parameters were successively substituted in place of the measured ones to yield predictions two through six from the model: Prediction 2, normal predicted $\dot{Q}_{\mathrm{Cmax}_{\max }}$; Prediction 3, normal $\dot{Q}_{\mathrm{Cmax}}$ and normal oxygen extraction (i.e., $\mathrm{Sv}_{2}-0.25 \mathrm{Sc}^{\prime} \mathrm{O}_{2}$ ) Prediction 4 , normal $\dot{Q}_{C \max }, \mathrm{O}_{2}$ extraction, and $\mathrm{V}_{\mathrm{D}} / \mathrm{V}_{\mathrm{T}}=0.25$; Prediction 5, normal $\dot{Q}_{C_{\max }}, \mathrm{O}_{2}$ extraction, $\mathrm{V}_{\mathrm{D}} / \mathrm{V}_{\mathrm{T}}$, and $\dot{\mathrm{V}}_{\mathrm{Emax}}$; Prediction 6, normal $\dot{Q}_{\mathrm{Cmax}_{\max }}, \mathrm{O}_{2}$ extraction, $\mathrm{V}_{\mathrm{D}} / \mathrm{V}_{\mathrm{T}}, \dot{\mathrm{V}}_{\mathrm{Emax}}, \mathrm{DM}_{\mathrm{Co}}$, and $\mathrm{V}_{\text {c }}$. Normal predicted $\dot{Q}_{\mathbf{C m a x}_{\max }}$ was calculated from the Fick equation assuming a normal predicted $\dot{\mathrm{VO}}_{2 \max }$ (13) and a pulmonary arteriovenous oxygen difference at peak exercise of $15 \mathrm{ml}$ oxygen $/ 100 \mathrm{ml}$ of blood.

mixed venous oxygen saturation $\left(\mathrm{S}_{\bar{v}} \mathrm{O}_{2}\right)$, dead space fraction $\left(\mathrm{V}_{\mathbf{D}} / \mathrm{V}_{\mathbf{T}}\right)$, maximal ventilation $\left(\dot{\mathrm{V}}_{\mathbf{E m a x}}\right)$, and diffusing capacity (DMco and $V_{C}$ ) in place of those which were actually measured; averages of the results for each of these successive predictions are summarized in Fig. 2 along with the correlation coefficients between measured and predicted values. The $\dot{\mathrm{V}}_{\mathrm{o}_{\max }}$ predicted by the model progressively increases in Fig. 2 from predictions 1 through 6 as input parameters are progressively normalized. Thus, for prediction no. 6 all values of the input parameters used for making the calculations were those normally expected for each patient and the average $\dot{\mathrm{V}}_{\mathrm{O}_{\mathrm{max}}}$ predicted therewith corresponds closely to the average expected normal $\dot{V}_{0_{2 m a x}}$. Scattergrams of the correlations between measured and predicted values by prediction no. 2 assuming a normal maximal cardiac output along with measured exercise values for all other input parameters (Table I) are given in Fig. 3. 

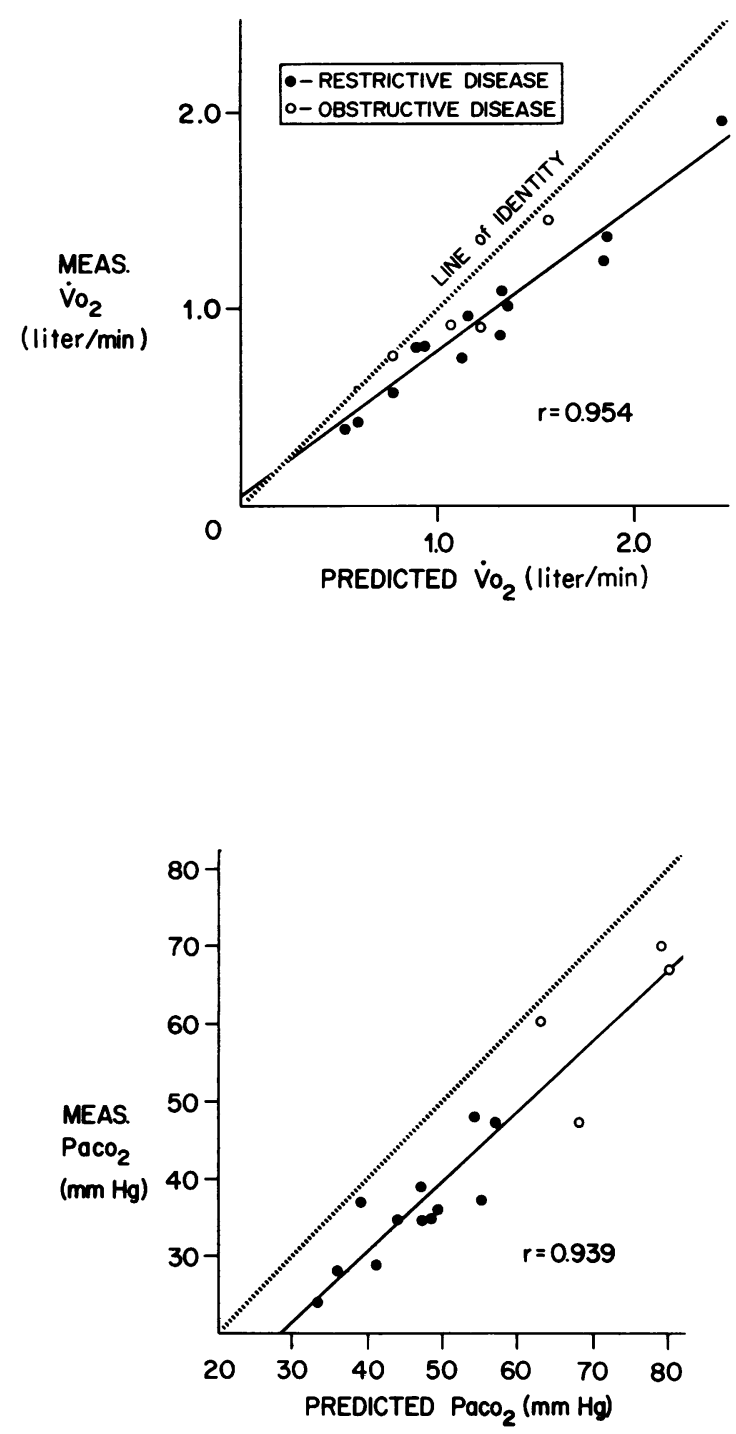
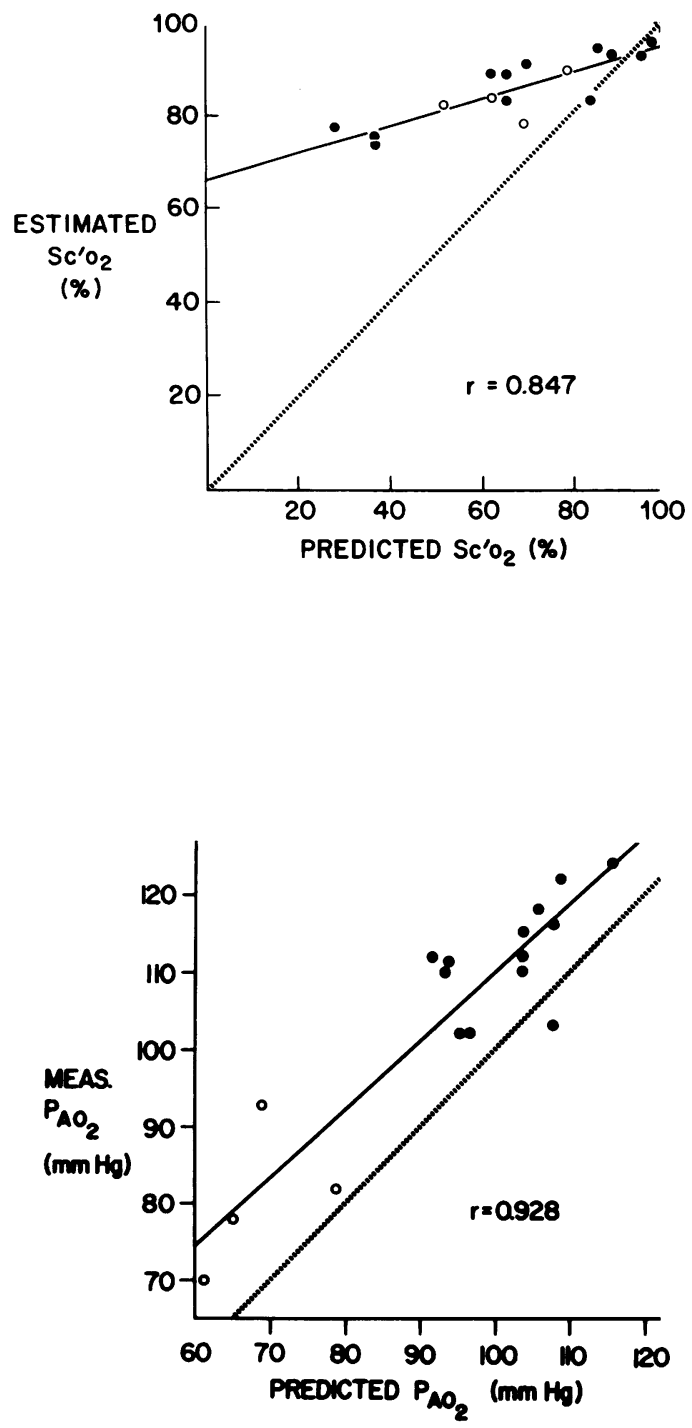

Figure 3 Comparison of measured (Meas.) values of $\mathrm{V}_{2 \max }, \mathrm{PaCO}_{2}, \mathrm{PAO}_{2}$, and $\mathrm{Sc}^{\prime} \mathrm{O}_{2}$ with those predicted from the model in the 16 patients with complete exercise data. Predictions were made from those parameters measured at peak exercise which are listed in the first column of Table I with the exception that a normal predicted maximal cardiac output was assumed (i.e., same as prediction 2 of Fig. 2).

Predictions by the model may be applied to all 23 studies by using parameters measured at rest if reasonable assumptions are made for exercise levels of $\mathrm{V}_{\mathrm{Amax}}, \dot{Q}_{\mathrm{Cmax}_{\max }}, \mathrm{S}_{\overline{\mathrm{V}} \mathrm{O}_{2}}$, and $\mathrm{R}$ and if allowances can be made for the changes which occur in $D_{M_{C O}}$ and $V_{C}$ from rest to exercise. Predictions in Fig. 4 were made assuming $\dot{\mathrm{V}}_{\mathrm{Amax}}=35 \mathrm{FEV}_{1}\left(1-\mathrm{V}_{\mathrm{D}} / \mathrm{V}_{\mathrm{T}}\right)$, assuming a normal maximal cardiac output, $75 \%$ extraction of the delivered oxygen (i.e., $\mathrm{S}_{\bar{v}} \mathrm{O}_{2}=0.25 \mathrm{Sc}^{\prime} \mathrm{O}_{2}$ ), and $\mathrm{R}$ of 1.0 , a $\mathrm{pH}$ of 7.4 , resting $\mathrm{DM}_{\mathrm{CO}}$, and a ratio of $\mathrm{V}_{\mathrm{C}} / \mathrm{D}_{\mathrm{M}}$ at peak exercise of 2.75. The correlation coefficient between $\dot{V}_{O_{2 m a x}}$ predicted with these approximations and measured $\dot{V}_{2 \max }$ were not significantly different from the correlation coefficient obtained when predictions were made with those input parameters actually measured at exercise.

\section{DISCUSSION}

In spite of excellent correlations between theoretical predictions and measurement, there is a systematic discrepancy between reductions in $\dot{V}_{2 m a x}$ predicted by the model and those actually measured. The average normal $\dot{\mathrm{V}}_{2 \max }$ based on age and body weight of the 15 patients who were completely studied was $2,330 \pm 672 \mathrm{ml} / \mathrm{min}(1 \mathrm{SD})$; average measured $\dot{V o}_{2 \max }$ was $976 \pm 389 \mathrm{ml} / \mathrm{min}$, a $59 \%$ reduction. Based on 
input data derived from actual measurements at peak exercise, the average prediction of $\dot{V}_{0_{\max }}$ from the model was $1,111 \pm 427 \mathrm{ml} / \mathrm{min}$ (prediction no. 1 in Fig. 2), a $52 \%$ reduction. Thus about $12 \%$ of the measured reduction (i.e., $(59-52) / 59 \times 100)$ remains unexplained by the model.

One source for error between predictions by the model and actual measurements arises because the model assumes uniform distribution of $D_{\mathbf{L}}, \dot{Q}_{\mathbf{C}}$, and $\dot{\mathrm{V}}_{\mathbf{A}}$ within the lung. Uneven distribution of these functional capacities with respect to each other reduces efficiency of gas transfer and will cause the measured $\dot{V}_{O_{2 \max }}$ to fall short of that predicted. We employed measured $V_{D} / V_{T}$ ratio in the prediction to partially correct for inefficient gas exchange due to functional inhomogeneity.

Another source of systematic error in predictions may arise from potential errors in measurement of DLco caused by inhomogeneity of diffusing capacity per unit lung volume $\left(D_{L_{C O}} / V_{A}\right)(20)$ and by alveolar sampling that is not representative of the lung as a whole. Systematic sampling errors were probably not large in the patients with predominantly restrictive disease since the breath-holding estimates of alveolar volume (mean $V_{A}=3.29 \pm 0.79$ ) by single breath neon dilution during DLCo measurements closely corresponded to plethysmographic measures of total lung capacity (mean total lung capacity (TLC) $=3.42 \pm 0.77)$; the correlation coefficient between paired estimates of TLC and $V_{A}$ is 0.855 implying that the samples were generally representative of the lung as a whole. Systematic underestimates of both $\dot{Q}_{c}$ and DLco from sampling errors are more probable in the obstructed patients in whom single-breath estimates of alveolar volume $(5.76 \pm 1.85)$ were systematically lower than nitrogen washout and plethysmographic measures of TLC $(7.72 \pm 1.28)$ by about $29 \%$; this should cause both $\dot{Q}_{\mathrm{C}}$ and $\mathrm{DL}_{\mathrm{CO}}$ to be abnormally low; in these instances the measured D $L_{c o}$ and $\dot{Q}_{c}$ may only reflect those portions of the diffusing capacity and blood flow which are available for gas exchange (2).

Another source of systematic error might arise from uncertainty in the estimate of $\mathrm{DL}_{2}$ from measurements of DLCo. Values of $\theta \mathrm{O}_{2}$ reported by Staub et al. (3) may be too high (23). If so, our predictions of $\dot{\mathrm{Vo}}_{2 \max }$ would be too high. There also are uncertainties in the value of $\theta_{\mathrm{CO}}$ employed to calculate $\mathrm{DM}_{\mathrm{CO}}$ since the relative permeability $(\lambda)$ of the erythrocyte membrane to the erythrocyte interior for $\mathrm{CO}$ and for $\mathrm{O}_{2}$ remains uncertain. We used a middle value $(\lambda=2.5)$ for calculating $\theta_{\mathrm{CO}}$; variations in $\lambda$ between $\infty$ and 1.5 cause $a \pm 12 \%$ uncertainty in our average estimate of $\mathrm{DM}_{\mathrm{MCO}}$.

Most aspects of oxygen transport at exercise, both repiratory and circulatory, have been affected in these patients; hence, a primary source of disability may not be evident. The model, however, provides a theoretical

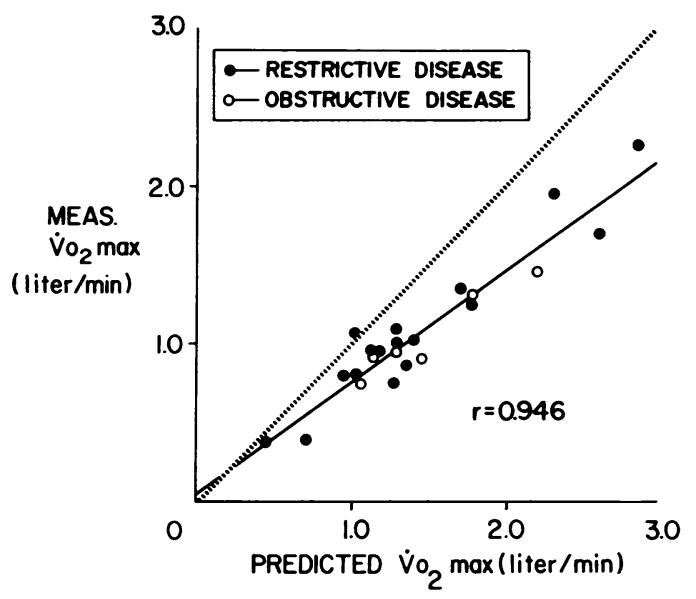

FIgURE 4 Relationship between maximal oxygen consumption which was measured (Meas.) and maximal oxygen consumption which was predicted from the model for all 22 subjects. Predictions were made assuming a normal maximal cardiac output, $75 \%$ extraction of the delivered oxygen, $\dot{\mathrm{V}}_{\text {Emax }}$ estimated as $35 \times \mathrm{FEV}_{1}$, resting DMco, resting $\mathrm{V}_{\mathrm{D}} / \mathrm{V}_{\mathrm{T}}, \mathrm{pH}_{\mathrm{a}}=7.40$, and $\mathrm{R}=1.0$.

framework for interpreting the relative importance of different steps in the oxygen transport chain.

Average $\dot{Q}_{C_{\max }}$ was $9.5 \mathrm{l} / \mathrm{min}$, average predicted being $15.6 \mathrm{l} / \mathrm{min}$. However normalizing maximal cardiac output in the model only raises the average predicted $\dot{V}_{O_{\max }}$ from 1,111 to $1,247 \pm 503 \mathrm{ml} / \mathrm{min}$. Furthermore raising the peripheral oxygen extraction from the average of $69 \%$ of that delivered to a normal $75 \%$ increases the average predicted $\dot{\mathrm{V}}_{\mathrm{O}_{\max }}$ only 76 $\mathrm{ml} / \mathrm{min}$ more. Assuming that $75 \%$ of the oxygen delivered is extracted in the tissues is arbitrary and we could have assumed instead some minimum mixed venous oxygen tension at peak exercise; however allowing mixed venous oxygen tension to vary between 25 and $10 \mathrm{~mm} \mathrm{Hg}$ only changes the predicted $\dot{\mathrm{V}}_{\mathrm{O}_{2 \max }}$ between 1,163 and $1,393 \mathrm{ml} / \mathrm{min}$. Thus, over a wide range the assumptions about mixed venous oxygen saturation or $\mathrm{Po}_{2}$ are not critical and an $80 \%$ increase in circulatory transport capacity in these patients could have afforded only about a $20 \%$ increase in oxygen consumption whether circulatory transport is increased by raising cardiac output or by more complete extraction of oxygen in tissues. These results suggest that at peak exercise most of the patients were operating near the upper limit of oxygen transport imposed by impaired lung function so that any enhancement of oxygen transport capacity expected from further increments of cardiac output and/or oxygen extraction would be largely offset by more desaturation of arterial blood. This is illustrated in Fig. 2 by the sharp fall in $\mathrm{Sc}^{\prime} \mathrm{O}_{2}$ between predictions 1 and 3 in the face of small increments in predicted $\dot{V}_{o_{2 m a x}}$ and explains why pre- 


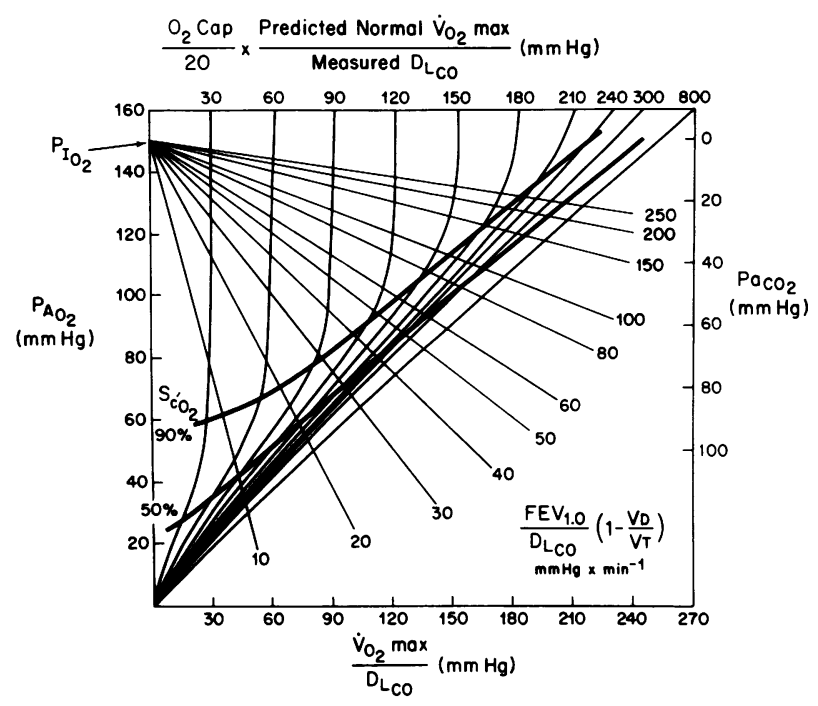

FIgURE 5 A nomogram for predicting oxygen consumption, alveolar gas tensions, and oxygen saturation of blood leaving the lung at peak exercise from the normal predicted maximal oxygen consumption and from resting measurements of $F E V_{1}$, $\mathrm{DL}_{\mathrm{CO}}$, and $\mathrm{V}_{\mathrm{D}} / \mathrm{V}_{\mathrm{T}}$.

dictions by the model in patients with severe lung disease are insensitive to errors in assumed values for maximal cardiac output or fractional oxygen extraction.

The cause for the low maximal cardiac output in these patients is not clear. The average slope of the relationship between pulmonary blood flow and oxygen consumption was normal, though in some patients the pulmonary blood flow tended to be slightly high for the level of oxygen intake (i.e., the intercept of the relationship was shifted). These data are consistent with those of Wade and Bishop indicating that cardiac output remains normal with respect to oxygen consumption in most patients with alveolar capillary block syndrome and patients with emphysema (24). The results also are consistent with those obtained in normal subjects exposed to chronic hypoxia at high altitudes who exhibit a low maximal cardiac output but a normal relationship between cardiac output and oxygen consumption $(25,26)$. The low maximal cardiac output in our patients or that in normal subjects at high altitude may reflect in part the chronic restriction of activity imposed by impaired gas exchange, mechanical restriction imposed by an increased pulmonary vascular resistance, or premature curtailment of work load by subjective discomfort from the combined influences of increased work of breathing, hypoxia, and acidosis. A fourth possibility is suggested by the work of Liang and Hood (27) showing that peripheral oxygen consumption per se may be the primary drive determining the cardiac output; then if oxygen consumption is curtailed by a primary trans- port bottleneck in the lungs, a low maximal cardiac output would be an expected consequence. For example, if a fixed linear relationship is assumed between $Q_{\mathrm{C}}$ and $\dot{\mathrm{V}}_{2}$ in equation $4, \dot{Q}_{\mathrm{Cmax}}$ and $\mathrm{S}_{\overline{\mathrm{V}} \mathrm{O}_{2}}$ can be eliminated as predicting parameters in the model; the model then predicts a reduction in $\dot{Q}_{\mathrm{Cmax}}$ as a consequence of an imposed transport bottleneck in the lungs. But whatever the cause the low maximal cardiac output may be protective of vital organs since further increments of pulmonary blood flow or peripheral oxygen extraction in these circumstances may significantly aggravate arterial hypoxemia yet can achieve little further increase in oxygen delivery to exercising muscle.

The relative importance of uneven distribution of ventilation and perfusion as a source of impaired oxygen transport can be further assessed with the model by examining the sensitivity of predictions to changes in the assumed dead space ventilation. Hence, if in addition to the assumption of a normal $\dot{Q}_{\mathrm{Cmax}}$ and normal peripheral oxygen extraction we also assume an approximately normal ratio of $V_{D} / V_{T}(0.25)$ the average $\dot{V}_{0_{\max }}$ predicted by the model further increases to $1,507 \pm 576 \mathrm{ml} / \mathrm{min}$ (prediction 4 in Fig. 2) but even then there remain two-thirds of the measured reduction in $\dot{V}_{2 \max }$ which should have been evident in these patients even if there had been no reduction in maximal cardiac output and there had been approximately uniform matching of ventilation, perfusion, and diffusing capacity in the lung. Furthermore, the correlation between measured and predicted $\dot{\mathrm{V}}_{2 \max }$ remains high $(r=0.965)$ so that $93 \%$ of the variance in $\dot{V}_{o_{2} \max }$ is still explained by the model even when normal predicted levels of $\dot{Q}_{\mathrm{Cmax}}, \mathrm{S} \bar{V}_{2}$, and $\mathrm{V}_{\mathrm{D}} / \mathrm{V}_{\mathrm{T}}$ are substituted for those which were measured at exercise. Thus, most of the information pertiennt to predicting $\dot{V}_{o_{\max }}$ in these patients and pertinent to explaining the variability among patients is available from the absolute reductions in diffusing capacity and ventilatory capacity.

The parameters used for making the above predictions were all obtained at exercise and the computations would be time consuming without a computer. For practical purposes we would like to estimate the limitation imposed by lung disease on maximal oxygen consumption from simple resting measurements of lung function without a computer and would prefer the simple measurement of $D_{L_{C O}}$ rather than measurements of $\mathrm{DM}_{\mathrm{CO}}$ and $\mathrm{V}_{\mathrm{C}}$ for making predictions. Hence, we constructed a nomogram for predicting maximal oxygen consumption employing resting measurements of $\mathrm{DLCO}_{\mathrm{C}}, \mathrm{FEV}_{1}$, and $\mathrm{V}_{\mathrm{D}} / \mathrm{V}_{\mathrm{T}}$ (Fig. 5) and tested the application of the nomogram with the present data. The methods of constructing the nomogram and its application are explained in the appendix. 
Employing this nomogram a correlation coefficient of 0.942 is obtained comparing predicted and measured $\mathrm{Vo}_{\text {max }}$. However the systematic discrepancy which was discussed earlier remains so that average measured $\dot{V}_{0_{2 \max }}$ is $75 \%$ of that predicted from the nomogram. The regression equation relating the measured and nomographic values is

$$
\begin{aligned}
& \text { measured } \dot{V}_{0_{2 \max }}(\text { milliliter/minute) } \\
& \left.\quad=0.7 \text { (nomographic } \dot{\mathrm{V}}_{\mathrm{O}_{\max }}\right)+45 \pm 1.50(\mathrm{SEE}) .
\end{aligned}
$$

The results suggest that reductions in maximal oxygen consumption can be predicted with reasonable accuracy among patients with a variety of different lung diseases from relatively simple measures of resting lung function. Discrepancies between measured maximal oxygen consumption and that predicted by these methods should suggest inordinate reduction of maximal cardiac output or inordinate degrees of mismatching among blood flow, ventilation, and diffusing capacity within the lung.

\section{APPENDIX}

Construction of the nomogram (Fig. 5). The nomogram is based upon equations 1, 4, and 6 in the Methods but some parameters had to be normalized and simplifying assumptions had to be made to make predictions from a single nomogram. This was accomplished as follows: in each of the above equations $\dot{\mathrm{V}}_{2}, \dot{\mathrm{V}}_{\mathrm{A}}$, and $\dot{\mathrm{Q}} \mathrm{c}$ were normalized with respect to DMco. Assuming 75\% extraction of the delivered oxygen, we substituted $0.75 \mathrm{Sc}^{\prime} \mathrm{O}_{2}$ for $\left(\mathrm{Sc}^{\prime} \mathrm{O}_{2}-\mathrm{Svo}_{2}\right)$ in equations 4 and 6 . Hence,

$$
\begin{aligned}
& \mathrm{PAO}_{2}=\mathrm{PI}_{\mathrm{O}_{2}}-863 \frac{\left(\dot{\mathrm{V}}_{\mathrm{O}_{2}} / \mathrm{DM}_{\mathrm{CO}}\right)}{\left(\dot{\mathrm{V}}_{\mathrm{A}} / \mathrm{DM}_{\mathrm{CO}}\right)}\left[1-\mathrm{F}_{\mathrm{IO}_{2}}(1-\mathrm{R})\right] \\
& \dot{\mathrm{VO}}_{2} / \mathrm{DM}_{\mathrm{CO}}=\left(\dot{\mathrm{Q}}_{\mathrm{C}} / \mathrm{DM}_{\mathrm{CO}}\right)\left(0.75 \mathrm{Sc}^{\prime} \mathrm{O}_{2}\right)(\mathrm{cap}) / 100 \\
& \dot{\mathrm{VO}}_{2} / \mathrm{DM}_{\mathrm{CO}}=\frac{\left(\mathrm{V}_{\mathrm{C}} / \mathrm{DM}_{\mathrm{CO}}\right) 0.75 \mathrm{Sc}^{\prime} \mathrm{O}_{2}}{\int_{\mathrm{S}_{\overline{\mathrm{VO}}}}^{\mathrm{Sc}^{\prime} \mathrm{O}_{2}}\left(\frac{\mathrm{V}_{\mathrm{C}}}{1.2 \mathrm{DM}_{\mathrm{CO}}}+\frac{1}{\theta \mathrm{O}_{2}}\right) \frac{\mathrm{dSO}_{2}}{\left(\mathrm{P}_{\mathrm{A}_{2}}-\mathrm{PCO}_{2}\right)}}
\end{aligned}
$$

Both numerator and denominator of equation 9 contain $\mathrm{V}_{\mathbf{c}} / \mathrm{DM}_{\mathrm{co}}$; since $\mathrm{V}_{\mathbf{c}} / \mathrm{DM}_{\mathrm{co}}$ tends to be large with respect to $1 / \theta \mathrm{O}_{2}$ in the denominator $\left(\mathrm{V}_{\mathrm{c}} / \mathrm{DM}_{\mathrm{co}}\right.$ in numerator and denominator tend to cancel) so that predictions from equation 9 are insensitive to errors in the assumed ratio of $V_{C} / D M_{C o}$ (e.g., changing $\mathrm{V}_{\mathbf{c}} / \mathrm{D}_{\mathbf{M}_{\mathrm{Co}}}$ from 2 to 3 causes the average prediction of $\mathrm{VO}_{2 \max }$ in our patients to change by only $39 \mathrm{ml} / \mathrm{min}$ ). The average $V_{c} / D_{M_{c o}}$ at peak exercise in our patients was 2.75 which is close to the average of 2.3 seen in normal subjects. We assumed $V_{C} / D_{M}$ co to be 2.75 in constructing the nomogram.

Exercise DMco correlates closely with resting $\mathrm{DL}_{\text {co }}$ $(r=0.954)$ and $\mathrm{DM}_{\text {Co }} \cong 1.80 \mathrm{DL}_{\mathrm{Co}}$; hence we substituted 1.8 DL $\mathrm{L}_{\text {co }}$ for DMco in equations 7,8 , and 9. $\dot{V}_{A_{\max }}$ in equation 7 was approximated by $\dot{V}_{A_{\max }}=35 \mathrm{FEV}_{1}\left(1-\mathrm{V}_{\mathrm{D}} / \mathrm{V}_{\mathrm{T}}\right)$. Normal $\dot{Q}_{\mathbf{C m a x}_{\max }}$ in equation 8 can be estimated from the normal predicted maximal oxygen consumption employing the Fick equation and assuming a pulmonary arteriovenous oxygen difference of $15 \mathrm{ml} / 100 \mathrm{ml}$ of blood. With the above modifi- cations, equations 7,8 , and 9 simplify to the following:

$$
\begin{aligned}
\mathrm{P}_{\mathrm{A}_{2}} & =\mathrm{PI}_{\mathrm{O}_{2}}-\left[\frac{24.7}{\left.\mathrm{FEV}\left(1-\mathrm{V}_{\mathrm{D}} / \mathrm{V}_{\mathrm{T}}\right) / \mathrm{DL}_{\mathrm{CO}}\right)}\right] \\
\times \dot{\mathrm{VO}}_{2} / \mathrm{DL}_{\mathrm{CO}} & \\
\dot{\mathrm{V}}_{2} / \mathrm{DL}_{\mathrm{CO}} & =\left[\frac{(\mathrm{cap})}{20} \frac{\text { normal predicted } \mathrm{VO}_{2 \mathrm{max}}}{\mathrm{DL}_{\mathrm{CO}}}\right] \mathrm{Sc}^{\prime} \mathrm{O}_{2} \\
\dot{\mathrm{VO}}_{2} / \mathrm{DL}_{\mathrm{CO}} & =\frac{3.71 \mathrm{Sc}^{\prime} \mathrm{O}_{2}}{\int_{0.25 \mathrm{Sc}^{\prime} \mathrm{O}_{2}}^{\mathrm{Sc}^{\prime} \mathrm{O}_{2}}\left(2.29+\frac{1}{\theta \mathrm{O}_{2}}\right) \frac{\mathrm{dSO}_{2}}{\left(\mathrm{PA}_{\mathrm{A}_{2}}-\mathrm{PCO}_{2}\right)}}
\end{aligned}
$$

The nomogram (Fig. 5) represents a graphic solution for these three equations. The curved isopleths radiating from the origin represent the relationships between $\mathrm{PA}_{\mathrm{O}_{2}}$ and $\mathrm{VO}_{2} / \mathrm{DL}_{\mathrm{Co}}$ for equations 11 and 12 ; each isopleth represents a different ratio of

$$
\frac{\text { normal predicted } \dot{\mathrm{Vo}}_{2 \max }}{\text { measured } \mathrm{DL}_{\mathrm{co}}} \times \frac{\mathrm{O}_{2} \text { cap }}{20} \text { in } \mathrm{mm} \mathrm{Hg} .
$$

The straight isopleths represent the linear relationship between $\mathrm{VO}_{2} / \mathrm{DL}_{\mathrm{CO}}$ and $\mathrm{PAO}_{\mathrm{A}_{2}}$ defined by equation 10 ; each

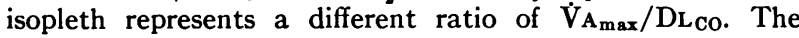
latter isopleths intersect the ordinate at the inspired tracheal $\mathrm{PO}_{2}\left(\mathrm{P}_{\mathrm{O}_{2}}\right)$; if inspired oxygen tension changes, only the intercept $\left(\mathrm{PI}_{\mathrm{O}_{2}}\right)$ needs to be changed, i.e., slopes remain fixed. Hence, if isopleths reflecting equation 10 are constructed as a separate transparent plastic overlay the nomogram may be used to predict $\hat{V}_{2 \max }$ at inspired oxygen tensions other than $150 \mathrm{~mm} \mathrm{Hg}$ simply by shifting the overlay to yield the appropriate $\mathrm{PI}_{\mathrm{O}_{2}}$.

The intersection of an isopleth representing equations 11 and 12 with one representing equation 10 yields the expected $\mathrm{VO}_{2 \max } / \mathrm{DL}$ co, $\mathrm{PAO}_{2}$, and $\mathrm{PaCO}_{2}$ for corresponding ratios of (predicted normal $\left.\dot{V}_{\mathbf{2}_{\max }}\right) /\left(\right.$ measured $\mathrm{DL}_{\mathrm{CO}}$ ), and $\dot{\mathrm{V}}_{\mathbf{A m a x}} /$ DL $_{\text {co }}$ [i.e., $\left(35 \mathrm{FEV}_{1} / \mathrm{DL}_{\mathrm{Co}}\right)\left(1-\mathrm{V}_{\mathrm{D}} / \mathrm{V}_{\mathrm{T}}\right)$ ]. The saturation isopleths (one for $90 \%$ and one for $50 \%$ ) have been added to facilitate interpretation. If the nomographic solution lies above and to the left of the $90 \%$ saturation isopleth, it suggests that the patient will be limited primarily by maximal cardiac output and completeness of tissue oxygen extraction rather than by his lungs. If the solution occurs below and to the right of the $90 \%$ saturation isopleth, exercise should be limited by the lung's ability to oxygenate the blood and/or eliminate carbon dioxide.

Patient I. M. exemplifies use of the nomogram. Obtain from Table I that $\mathrm{FEV}_{1}=650 \mathrm{ml}$, from Table II that resting $\mathrm{V}_{\mathrm{D}} / \mathrm{V}_{\mathrm{T}}=0.52$ and resting $\mathrm{DL}_{\mathrm{Co}}=19.2 \mathrm{ml} / \mathrm{min} / \mathrm{mmHg}$, and from Table III that $\mathrm{O}_{2}$ capacity $=19.9$. Employing these resting data to predict $\mathrm{V}_{2 \max }$ select the appropriate curvilinear isopleth $=\frac{1,562}{19.2} \times \frac{19.9}{20}=81$ and then select the appropriate irentilation isopleth $=\frac{650}{19.2} \times(1-0.52)=16$. The intersection at these two isopleths yields $\frac{\dot{\mathrm{V}}_{2 \max }}{\mathrm{DL}_{\mathrm{co}}}=58$; therefore the normographic prediction of $\dot{V}_{2 \max }=58 \times 19.2$ $=1,114 \mathrm{ml} / \mathrm{min}$.

\section{ACKNOWLEDGMENTS}

Miss Patricia Wells and Mrs. Sharon Smith both provided valuable assistance in typing and proofreading the manuscript and Tables. 
This work was supported by U. S. Public Health Service SCOR grant no. 32343 from the National Heart and Lung Institute.

Dr. Wehr was supported by a fellowship from U. S. Public Health Service Training grant HL 05182 from the National Heart and Lung Institute.

\section{REFERENCES}

1. Johnson, R. L., Jr. 1967. Pulmonary diffusion as a limiting factor in exercise stress. Circ. Res. 20 (Suppl. 1): I-154-I-160.

2. Shephard, R. J. 1969. The validity of the oxygen conductance equation. Int. Z. angew. Physiol. 28: 61-75.

3. Staub, N. C., J. M. Bishop, and R. E. Forster. 1962. Importance of diffusion and chemical reaction rates in $\mathrm{O}_{2}$ uptake in the lung. $J$. Appl. Physiol. 17: 21-27.

4. Johnson, R. L., Jr., H. F. Taylor, and A. C. DeGraff, Jr. 1965. Functional significance of a low pulmonary diffusing capacity for carbon monoxide. J. Clin. Invest. 44: 789-800.

5. Reedy, T., J. T. Davis, A. C. DeGraff, W. F. Miller, M. Ziff, and B. D. Fallis. 1963. Chronic progressive lung disease of unknown etiology. Tex. State J. Med. 59 : 43-49.

6. DeGraff, A. C., Jr., H. F. Taylor, J. W. Ord, T. H. Chaung, and R. L. Johnson, Jr. 1965. Exercise limitation following extensive pulmonary resection. J. Clin. Invest. 44: 1514-1522.

7. Shuey, C. B., Jr., A. K. Pierce, and R. L. Johnson, Jr. 1969. An evaluation of exercise tests in chronic obstructive lung disease. J. Appl. Physiol. 27 : 256-261.

8. Scholander, P. F. 1947. Analyzer for accurate estimation of respiratory gases in one-half cubic centimeter samples. J. Biol. Chem. 167 : 255-250.

9. DuBois, A. B., S. Y. Botelho, G. N. Bedell, R. Marshall, and J. H. Comroe, Jr. 1956. A rapid plethysmographic method for measuring thoracid gas volume: a comparison with nitrogen washout method for measuring functional residual capacity in normal subjects. J. Clin. Invest. 35: 322-326.

10. Johnson, R. L., Jr., W. S. Spicer, J. M. Bishop, and R. E. Forster. 1960. Pulmonary capillary blood volume, flow and diffusing capacity during exercise. J. Appl. Physiol. 15: 893-902.

11. Lawson, W. H., Jr. 1970. Rebreathing measurements of pulmonary diffusing capacity for $\mathrm{CO}$ during exercise. J. Appl. Physiol. 29: 896-900.

12. Roughton, F. J. W., and R. E. Forster. 1957. Relative importance of diffusion and chemical reaction rates in determining rate of exchange of gases in the human lung, with special reference to true diffusing capacity of pulmonary membrane and volume of blood in the lung capillaries. J. Appl. Physiol. 11 : 290-302.
13. Åstrand, T. 1960. Aerobic work capacity in men and women with special reference to age. Acta Physiol. Scand. 49(Suppl. 1969) : 1-92.

14. Burrows, B., A. H. Niden, W. R. Barclay, and J. E. Kasik. 1965. Chronic obstructive lung disease. II. Relationship of clinical and physiologic findings to the severity of airways obstruction. Am. Rev. Respir. Dis. 91 : 665-678.

15. Miller, W. F., R. L. Johnson, Jr., and N. Wu. 1969. Relationships between maximal breathing capacity and timed expiratory capacities. J. Appl. Physiol. 14: 510-516.

16. Lieberman, D. A., J. A. Faulkner, A. B. Craig, Jr., and L. C. Maxwell. 1973. Performance and histochemical composition of guinea pig and human diaphragm. J. Appl. Physiol. 34: 233-237.

17. Reeves, J. T., R. F. Grover, S. G. Blount, Jr., and G. F. Filley. 1961. Cardiac output response to standing and treadmill walking. J. Appl. Physiol. 16: 283-288.

18. Mitchell, J. H., B. J. Sproule, and C. B. Chapman. 1958. The physiological meaning of the maximal oxygen intake test. J. Clin Invest. 37 : 538-547.

19. Saltin, B., G. Blomqvist, J. H. Mitchell, R. L. Johnson, Jr., K. Wildenthal, and C. B. Chapman. 1968. Response to exercise after bed rest and after training. A longitudinal study of adaptive changes in oxygen transport and body composition. Circulation. 38 (Suppl. VII) : VII-1-VII-78.

20. Forster, R. E., W. S. Fowler, and D. V. Bates. 1954. Considerations on the uptake of cardon monoxide by the lungs. J. Clin. Invest. 33: 1128-1134.

21. Lewis, B. M., T. H. Lin, F. E. Noe, and E. J. HayfordWelsing. 1959. The measurement of pulmonary diffusing capacity for carbon monoxide by a rebreathing method. J. Clin. Invest. 38: 2073-2086.

22. Lewis, B. M., E. J. Hayford-Welsing, A. Furusho, and L. C. Reed, Jr. 1961. Effect of uneven ventilation on pulmonary diffusing capacity. J. Appl. Physiol. 16: 679-683.

23. Holland, R. A. B., and R. E. Forster, 1966. The effect of size of red cells on the kinetics of their oxygen uptake. J. Gen. Physiol. 49 : 727-742.

24. Wade, O. L., and J. M. Bishop. 1962. Cardiac Output and Regional Blood Flow. Philadelphia. F. A. Davis. pp. 149-170.

25. Pugh, L. G. C. E. 1964. Cardiac output in muscular exercise at $5800 \mathrm{~m}(19,000 \mathrm{ft})$. J. Appl. Physiol. 19: 441-447.

26. Saltin, B., R. F. Grover, C. G. Blomqvist, L. H. Hartley, and R. L. Johnson, Jr. 1968. Maximal oxygen uptake and cardiac output after 2 weeks at $4,300 \mathrm{~m}$. J. Appl. Physiol. 25 : 400-409.

27. Liang, C. S., and W. B. Hood, Jr. 1973. Comparison of cardiac output responses to 2,4-dinitrophenol-induced hypermetabolism and muscular work. J. Clin. Invest. 52: 2283-2292. 